\title{
Synthesis of Long-subchain Hyperbranched Polypropylene Using Thermally Degraded Products as Precursor
}

Hanqing Jiang, ${ }^{\dagger,+}$ Shengda Wang ${ }^{\dagger, t}$, Yanhui Wang ${ }^{\dagger}$, Yaxian Wang ${ }^{\S}$, Liang Li $i^{\S}$, Li Ma ${ }^{*, \dagger}$, Dongmei Cui, ${ }^{\dagger,+}$ Tao Tang ${ }^{*},+, \neq$

†State Key Laboratory of Polymer Physics and Chemistry, Changchun Institute of Applied Chemistry, Chinese Academy of Sciences, Changchun 130022, China

*University of Science and Technology of China, Anhui 230026, China

${ }^{\S}$ ExxonMobil Asia Pacific Research and Development Co., Ltd., Shanghai 200241, China 


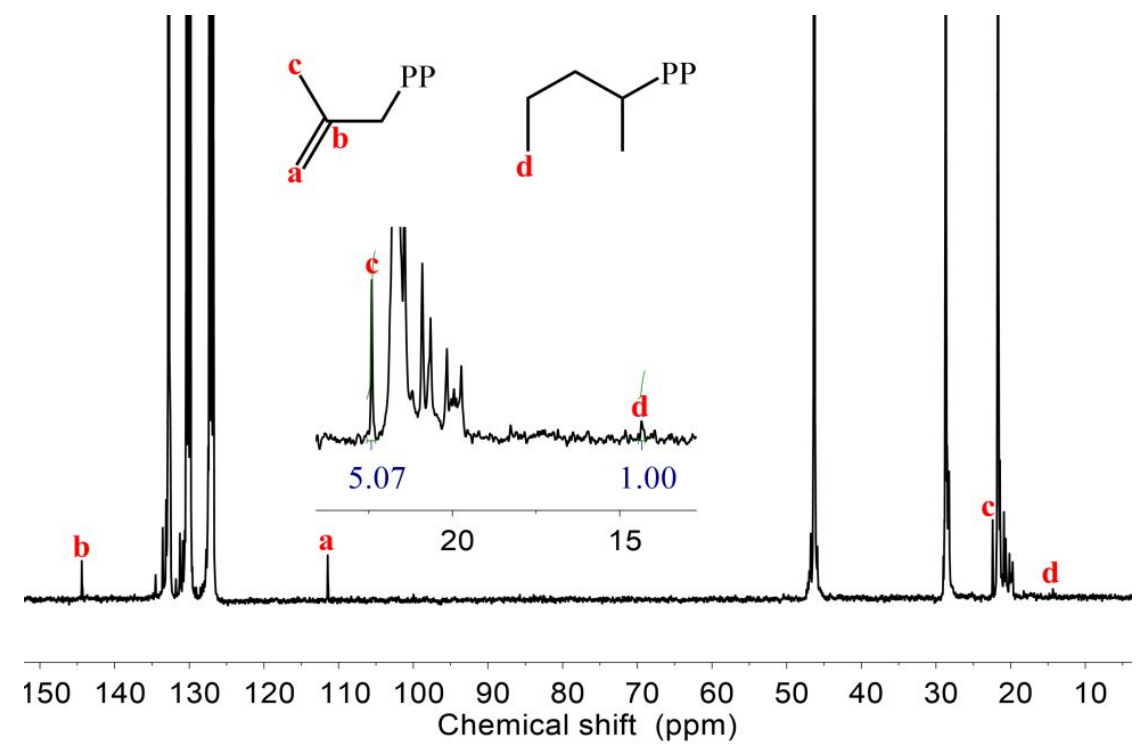

Figure S1 ${ }^{13} \mathrm{C}$-NMR spectra $\left(400 \mathrm{MHz}, 110^{\circ} \mathrm{C}, \mathrm{C}_{6} \mathrm{D}_{4} \mathrm{Cl}_{2}\right)$ of PP-TVD.

\section{Calculation for PP-TVD functionality ${ }^{1}$ :}

Assuming all the PP-TVD are linear, the value of functionality is calculated from the equation: $\%{ }_{f}=\mathrm{I}_{\mathrm{TVD}} /\left(\mathrm{I}_{\mathrm{TVD}}+\mathrm{I}_{n-\mathrm{Pr}}\right)$. $\mathrm{I}_{\mathrm{TVD}}$ is the methyl signal intensity of the isopropenyl end group, and $\mathrm{I}_{\mathrm{TVD}}+\mathrm{I}_{n-\mathrm{Pr}}$ is the methyl signal intensity of all end groups. Therefore, the functionality is $83.5 \%$.

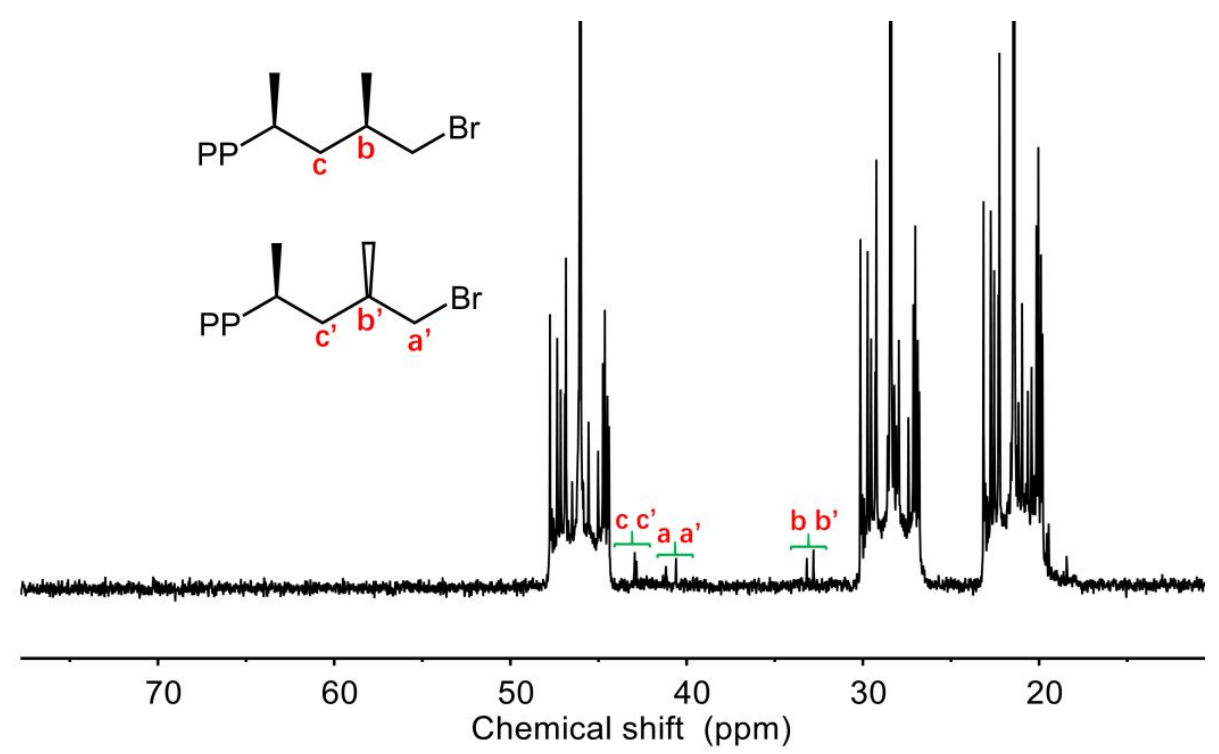

Figure S2 ${ }^{13} \mathrm{C}-\mathrm{NMR}$ spectra $\left(400 \mathrm{MHz}, 110{ }^{\circ} \mathrm{C}, \mathrm{C}_{6} \mathrm{D}_{4} \mathrm{Cl}_{2}\right)$ for $\mathrm{PP}-\mathrm{Br}$. 

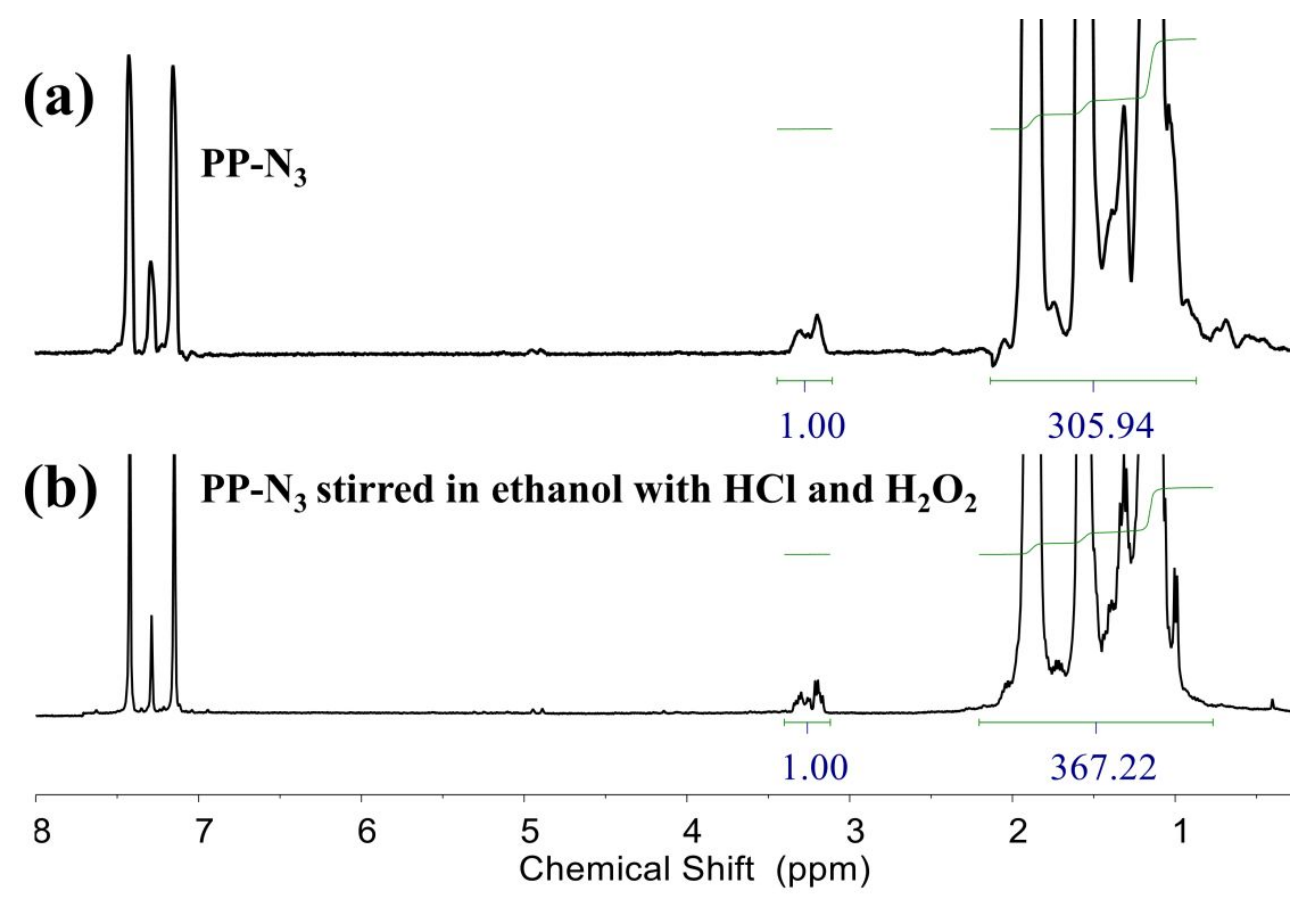

Figure $\mathbf{S 3}{ }^{1} \mathrm{H}-\mathrm{NMR}$ spectra $\left(400 \mathrm{MHz}, 110{ }^{\circ} \mathrm{C}, \mathrm{C}_{6} \mathrm{D}_{4} \mathrm{Cl}_{2}\right.$ ) of (a) $\mathrm{PP}-\mathrm{N}_{3}$ and (b) $\mathrm{PP}-\mathrm{N}_{3}$ stirred in ethanol with $\mathrm{HCl}$ and $\mathrm{H}_{2} \mathrm{O}_{2}$.

\section{Calculation for molecular weight of ideal LHB-PP:}

Calculation example for the ideal molecular weight of LHB-PP with different ratio of $n_{\mathrm{PP}-\mathrm{N} 3} / n_{\mathrm{TEB}}$ was shown below:

$$
M_{(L H B-P P)}=N_{p p-N_{3}} \times M_{w\left(p p-N_{3}\right)}+N_{T E B} \times M_{T E B}
$$

in which $\mathrm{N}_{\mathrm{pp}-\mathrm{N} 3}$ and $\mathrm{N}_{\mathrm{TEB}}$ are the number of PP-N3 and TEB respectively involved in each LHB-PPs macromolecule with different $n_{\mathrm{pp}-\mathrm{N} 3} / \mathrm{n}_{\mathrm{TEB}}$ value shown in Scheme 3 . $M_{w\left(p p-N_{3}\right)}$ is the $M_{\mathrm{w}}$ obtained from HT-GPC-LS and $M_{T E B}$ is the molecular weight of TEB.

For the one with $n_{\mathrm{PP}-\mathrm{N} 3} / n_{\mathrm{TEB}}=3$, the $\mathrm{N}_{\mathrm{pp}-\mathrm{N} 3}$ and $\mathrm{N}_{\mathrm{TEB}}$ are 3 and 1 in one LCB-PP macromolecule, therefore, the ideal molecular weight can be calculated as follows:

$$
M_{(L H B-P P)}=3 \times M_{w\left(p p-N_{3}\right)}+1 \times M_{T E B}=3 \times 18000+1 \times 150=54150
$$




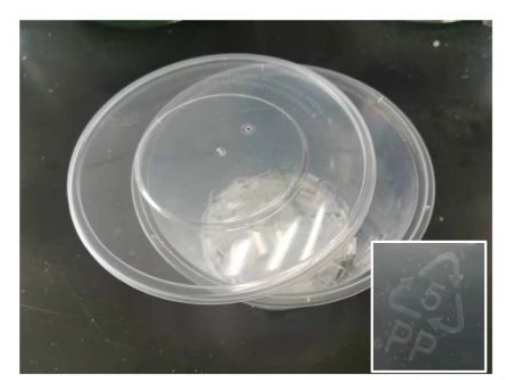

Degradation condition: $20 \mathrm{~g}, 380^{\circ} \mathrm{C}, 2.5 \mathrm{~h}$
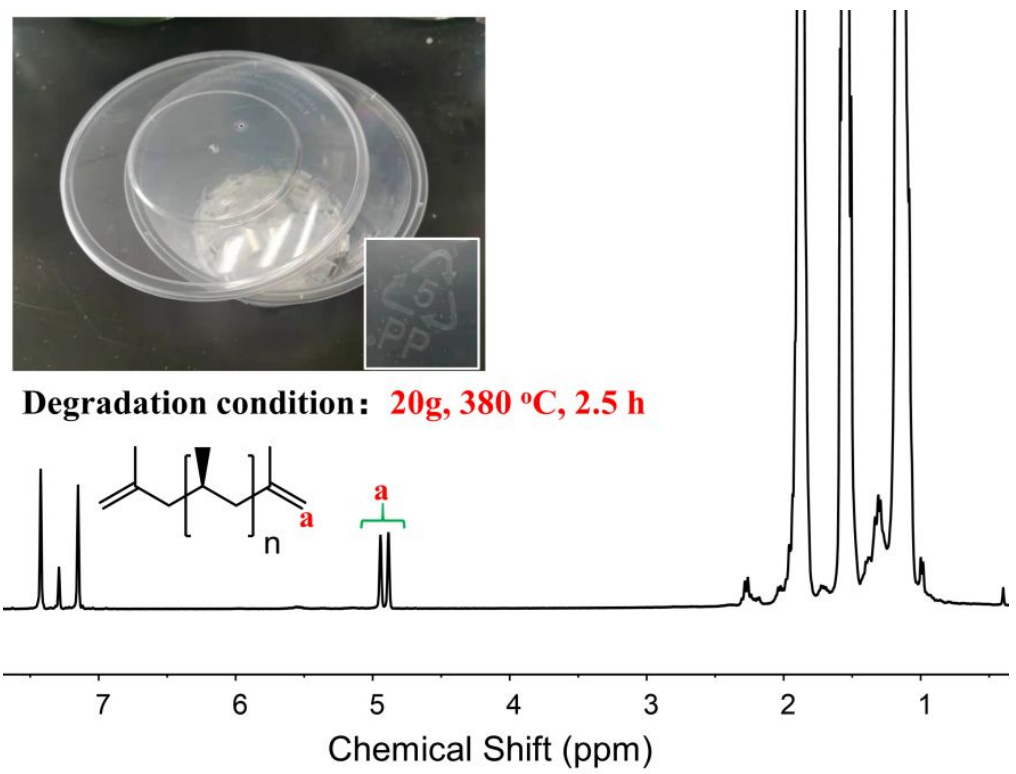

Figure $\mathbf{S 4}{ }^{1} \mathrm{H}-\mathrm{NMR}$ spectra $\left(400 \mathrm{MHz}, 110^{\circ} \mathrm{C}, \mathrm{C}_{6} \mathrm{D}_{4} \mathrm{Cl}_{2}\right)$ of thermal degradation of PP waste (food container).

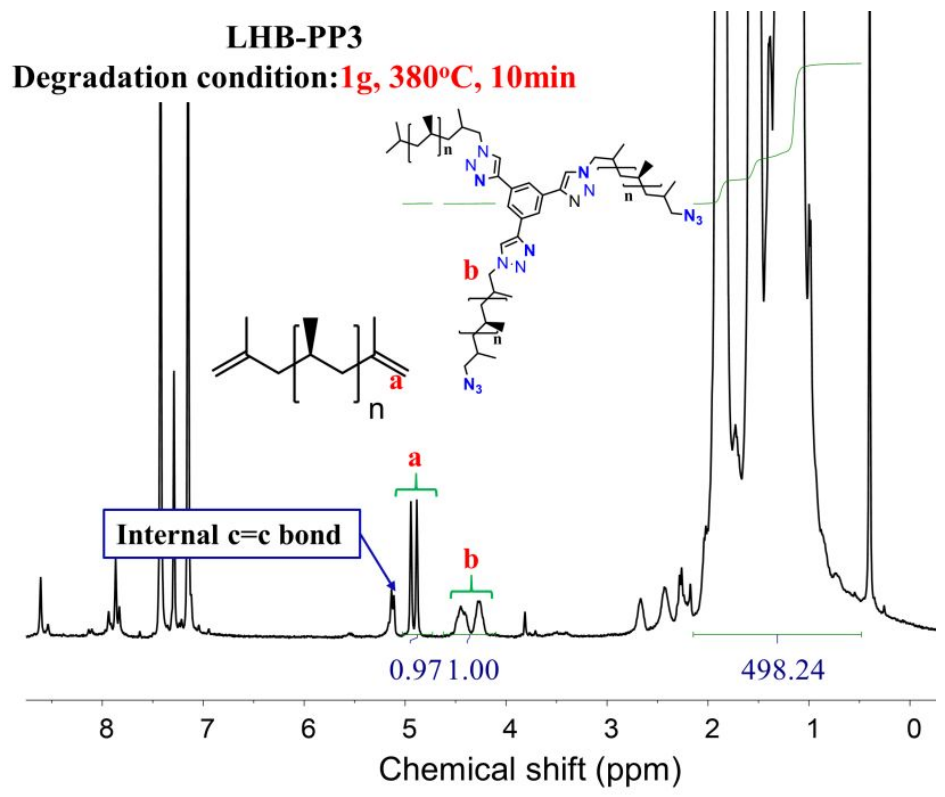

Figure S5 ${ }^{1} \mathrm{H}-\mathrm{NMR}$ spectra $\left(400 \mathrm{MHz}, 110^{\circ} \mathrm{C}, \mathrm{C}_{6} \mathrm{D}_{4} \mathrm{Cl}_{2}\right)$ of thermal degradation of LHB-PP3 


\section{Reference}

1. Sawaguchi, T.; Ikemura, T.; Seno, M., Preparation of .alpha.,.omega.-Diisopropenyloligopropylene by Thermal Degradation of Isotactic Polypropylene. Macromolecules 1995, 28 (24), 7973-7978. 